University of Nebraska - Lincoln DigitalCommons@University of Nebraska - Lincoln

2015

\title{
Criteria for Crack Deflection-Penetration in EBC Coated Ceramics: A Parametric Study
}

\author{
Ali Abdul-Aziz \\ NASA Glenn Research Center, Cleveland, Ohio, USA \\ Ramakrishna T. Bhatt \\ NASA Glenn Research Center, Cleveland, Ohio, USA \\ Joseph E. Grady \\ NASA Glenn Research Center, Cleveland, Ohio, USA
}

Follow this and additional works at: http://digitalcommons.unl.edu/nasapub

Abdul-Aziz, Ali; Bhatt, Ramakrishna T.; and Grady, Joseph E., "Criteria for Crack Deflection-Penetration in EBC Coated Ceramics: A Parametric Study" (2015). NASA Publications. 170.

http://digitalcommons.unl.edu/nasapub/170

This Article is brought to you for free and open access by the National Aeronautics and Space Administration at DigitalCommons@University of Nebraska - Lincoln. It has been accepted for inclusion in NASA Publications by an authorized administrator of DigitalCommons@University of Nebraska - Lincoln. 


\title{
Criteria for Crack Deflection-Penetration in EBC Coated Ceramics: A Parametric Study
}

\author{
ALI ABDUL-AZIZ, RAMAKRISHNA T. BHATT, and JOSEPH E. GRADY \\ NASA Glenn Research Center, Cleveland, Ohio, USA
}

Received 26 April 2013; accepted 22 April 2014.

This article discusses results obtained from a parametric study to analytically evaluate the impingement of a crack at the interface of an environmental barrier coating (EBC) and a monolithic Silicon nitride $\left(\mathrm{Si}_{3} \mathrm{~N}_{4}\right)$ layered ceramics substrate. The study establishes a correlation that leads to determine if the crack is arrested or advanced by either penetrating or deflecting along the EBC/substrate interface. A finite-element-based fracture mechanics methodology is utilized to perform these calculations. Critical parameters determining penetration-deflection conditions in relation to EBC's physical characteristics, such as porosity level, voids, and mini cracks, are determined for a single layer and multi-layered coating system coordinating the interactions between the EBCs (Mullite, Mullite mixture, Silicon nitride, etc.) and the substrate structure. Results showing thermo-mechanical stresses and stress/strain energy release relations with respect to crack penetration-deflection are presented and discussed as the crack is advanced.

Keywords: fracture mechanics, Silicon nitride, ceramics, EBC coating, crack penetration, deflection

\section{Nomenclature}

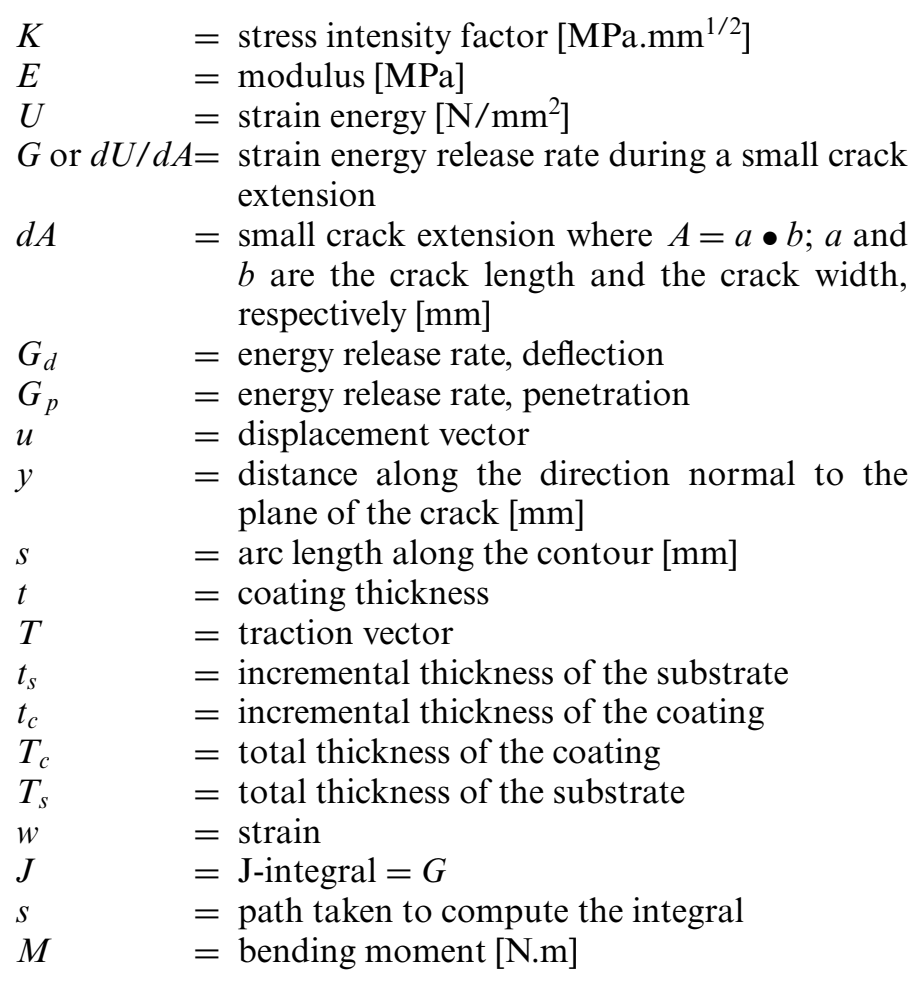

Address correspondence to Ali Abdul-Aziz, NASA Glenn Research Center, Optical Instrumentation and NDE Branch, 21000 Brook Park Road MS 6-1, Cleveland, OH 44135. E-mail: ali.abdul-aziz-1@nasa.gov

Color versions of one or more of the figures in the article can be found online at www.tandfonline.com/umcm.

\begin{tabular}{|c|c|}
\hline$P$ & $=$ load applied $[\mathrm{Pa}]$ \\
\hline$L$ and $b$ & $=$ beam length and width, respectively $[\mathrm{mm}]$ \\
\hline$E$ & $=$ Young modulus $[\mathrm{MPa}]$ \\
\hline$v$ & $=$ Poisson's ratio \\
\hline$h$ & $=$ thickness of the beam $[\mathrm{mm}]$ \\
\hline$\sigma_{i j}$ & $=$ stress at the interface \\
\hline$r$ and $\theta$ & $=$ radial distance and the polar angle \\
\hline$f_{i j}(\theta)$ & $=$ angular distribution of the singular stress field \\
\hline$\lambda$ & $=$ defines the strength of stress singularity \\
\hline$\alpha$ and $\beta$ & $=$ Dundurs bi-material parameters \\
\hline$E_{j}^{\prime}$ & $=E_{j}$ is for plane stress \\
\hline$E_{j}^{\prime}$ & $\begin{aligned}= & E_{j} /\left(1-v_{j}\right) \text { for plane strain }(1 \text { and } 2 \text { denote the } \\
& \text { material })\end{aligned}$ \\
\hline$\mu$ & $=$ shear modulus $[\mathrm{MPa}]$ \\
\hline$G_{d}$ & $\begin{array}{l}=\text { (material } 1) \text { is the strain energy release rate as- } \\
\text { sociated with the "deflected" crack or adhesive } \\
\text { failure }\end{array}$ \\
\hline$G_{p}$ & $\begin{array}{l}=(\text { material } 2) \text { is the strain energy release rate } \\
\text { associated with the "penetrated" crack (or co- } \\
\text { hesive failure of adjacent material) }\end{array}$ \\
\hline$G_{p c}$ & $=$ cohesive or penetrated fracture energy \\
\hline$G_{d c}$ & $\begin{array}{l}=\text { adhesive or deflected fracture energy, respec- } \\
\text { tively }\end{array}$ \\
\hline$K_{1}$ and $K_{2}$ & $=$ stress intensity factors for the interface crack \\
\hline$\varepsilon$ & constants \\
\hline
\end{tabular}

\section{Introduction}

Silicon nitride $\left(\mathrm{Si}_{3} \mathrm{~N}_{4}\right)$ layered ceramics with weak boron nitride $(\mathrm{BN})$ interphases have been previously manufactured in a conventional two-dimensional layered structure [1], as well 
as in a novel layered structure known as fibrous monolithic ceramic [2]. Notable properties were reported for both structures with high strength and fracture value [3]. However, variety of factors, such as residual stresses, process related flaws, and casting conditions, may influence the strength degradations. It also has been shown that in some layered materials, delamination cracks bowing out at the interface after propagating along the interface only a short distance [4-8]. Additionally, the coating applied by conventional methods on monolithic ceramics shows strength degradation by as much as $50 \%$ without a clear understanding of the mechanism of strength degradation $[9,10]$. Therefore, understanding the issues that control crack deflection and propagation along the interface is needed to maximize the energy dissipation capabilities of layered ceramics.

Furthermore, an additional aim of this work is to quantify and evaluate the effects of the crack driving forces in a layered environmental barrier coating (EBC) system for ceramic substrates using the fracture mechanics analytical approach under combined thermal and mechanical loading as a function of the coating thickness. In general, an EBC system consists of two or more layers of coating, in which each layer serves a specific purpose. The total thickness of the EBC applied depends on the components, and the coating can be applied by different processing methods depending on the intended microstructure and durability [11]. The analyses are performed to further guide optimizing the EBC system dimensions to help detect when the crack is deflected away from the substrate and contained mainly along the interface of the top two coating layers. It is implemented such as a self-sensing system that would provide an indication of coating degradation without affecting the substrate. Another goal is to acquire a quantitative measure of the crack initiating in the top EBC layer being deflected from the substrate rather than penetrating into the substrate.

Thus, a detailed summary describing a preliminary work for the deflection-penetration process at the EBC-ceramics substrate interface due to the effects of common crack driving forces, such as mechanical bending and temperature gradient, is being presented. The general approach applied in these analyses is to construct a detailed finite element model of the geometry and predict the energy release rate when a virtual crack is allowed to either grow along the interface or into the adjacent material. A discussion of the theoretical framework for calculating the fracture energy of the interface in a fourpoint bend (4PB) test, a technique in which the interface of interest is displayed at an elastic substrate, is untaken. This is followed by a discussion of the crack penetration and crack deflection at a bi-material interface. Finally, we present the finite element analysis of the 4PB specimen and significant findings related to the interpretation and reliability of $4 \mathrm{~PB}$ test data. Stress profiles under thermo-mechanical loading for crack advancement are presented as well as the stress-strain energy release rates for penetrating or deflecting cracks are discussed.

\section{Analytical Approach and Finite Element Analysis}

The finite element method is employed to determine the buildup of residual stresses for the proposed layered EBC system shown in Figure 1. The analyses covered analyzing a beam specimen with layered EBCs and Silicon nitride $\left(\mathrm{Si}_{3} \mathrm{~N}_{4}\right)$ ceramic substrate; specimen dimensions are $4 \times 3 \times 45 \mathrm{~mm}$ (Figure 1a). The beam is subjected to a four-point bend test as shown, i.e., Figure 1b. Three different EBC thicknesses of 25,75 , and $125 \mu \mathrm{m}$ are considered. The residual stresses developed during the coating application are incorporated into the analytical model. MSC/Patran [12] and MARC [13] finite element software were used as a CAD modeler for the geometric modeling of the specimen and as a solver for calculating the stress state in the coated beam configuration and the fracture mechanics calculations for various crack orientations and lengths.

The calculations are conducted under linear elastic conditions including temperature dependent material behavior. The Ortho-Temp option in the MARC [13] is employed to account for material property variation with temperature. Appropriate boundary conditions, such as thermal and mechanical, high temperature, burner flame, and cooling, are all included in the analyses. Table 1 [14] shows the material properties for the EBCs and the substrate used. The intermediate coat layer material properties are calculated using the rule of mixtures formulation. The beam geometry is constrained such as the experimental conditions imposed in the tests are imitated. Additional mechanical constraints are further added to suppress rigid body motion and eliminate over constraining factors, such as edge effects.

Only half of the bar specimen is considered for the analysis due to symmetry, i.e., Figure 2. The specimen is modeled with 8-node quad elements resulting in a model size consisting of 6000 elements and 18,000 nodes. Thermal environment generated by the plasma spray application is reproduced by an initial temperature of $1200^{\circ} \mathrm{C}$ applied to the entire structure followed by a cool down to room temperature of $21^{\circ} \mathrm{C}$.

Subsequently, stresses in the coating, the substrate, and the combined structure are all determined and evaluated. Figure 3 shows the finite element results for the in-plane stress distribution in the beam. It is noted from the fringe plot and it is anticipated that the maximum stress is at the coating-substrate interface region, which is due to the thermo-mechanical load and in particular to the through thickness thermal gradient. It further indicates how the beam is deflected due to the applied loads.

\section{Fracture Mechanics}

The fracture mechanics analysis is initiated by applying the J-Integral capability available in the MARC code [13] through numerical integration for a prescribed crack tip movement to evaluate the derivative of the strain energy with respect to the crack length. To overcome the difficulty that is usually encountered in the finite element fracture mechanics representation of the solution near the crack tip, the mesh is modeled so that the singularity is approximated with sufficient accuracy.

Many methods have been established to arrive at such an approximation; however, the most commonly used method is the degenerate form of the standard eight-node quadrilateral element. This method is usually referred to as the " $1 / 4$ " point singularity technique [15]. It is applied by using eight-node 
Table 1. Physical, thermal, and mechanical properties of stand-alone plasma sprayed coatings and SiC (MI) [14]

\begin{tabular}{lcccc}
\hline Material & Bend modulus $(\mathrm{GPa})$ & Bend strength $(\mathrm{MPa})$ & $\begin{array}{c}\text { Thermal expansion }(\alpha \\
10^{\left.-6 /{ }^{\circ} \mathrm{C}\right)}\end{array}$ & \multicolumn{1}{c}{ Poisson's ratio $(\gamma)$} \\
\hline $\begin{array}{l}\text { Barium strontium } \\
\text { aluminum silicate }\end{array}$ & 32 & 28 & 5.6 & 0.19 \\
(BSAS) & & & & 0.17 \\
Mullite & 45 & 28 & 5.8 & 0.184 \\
Mullite + BSAS & 37.4 & 28 & 5.57 & 0.24 \\
Silicon nitride $\left(\mathrm{Si}_{3} \mathrm{~N}_{4}\right)$ & 345 & 830 & 2.7 & \\
$\mathrm{SiC}(\mathrm{MI})$ & & & & \\
\hline
\end{tabular}

quarter of the edge length, and the edge opposite the crack is kept straight. Also, to justify the mesh density and minimize the near crack tip singularities, a real fine mesh density in the order of $10^{-4}$ in. elements at the crack tip was implemented, i.e., exaggerated view is shown in Figure 2.

The cracked geometries assumed are shown in Figure 4 for a crack propagating near the $\mathrm{EBC} / \mathrm{Si}$ interface, simulating experimentally observed EBC cracks under a cyclic heat-flux test. A typical cross-sectional view (scanning electron micrograph) is also shown in Figure 4, illustrating a crack and a coating sequence on a CMC substrate. The crack driving forces were calculated using the J-Integral technique through the virtual motion of a block of element surrounding the crack tip. The depth of the crack was always assumed to be $0.00254 \mathrm{~mm}$ above the interface. The crack length was manually varied to scale the node locations surrounding the crack tip in proportion to the desired crack length and crack depth.

\subsection{Stress Intensity Factor}

Calculation of the stress intensity factor will allow determination at which load increment crack propagation occurs. This is through calculating the elastic energy release rate, which is confined to a single parameter: the strength of the singularity in the elastic stress field at the crack tip. This stress intensity factor is usually denoted by the symbol $K$. The magnitude of $K$ depends on the crack length, the distribution and intensity of applied loads, and the geometry of the structure. Crack propagation will occur when any combination of these factors causes $K$ to be equal to or greater than the experimentally determined material threshold value [16]. The equation that relates $K$ to the energy release rate is given by the following relation [17]:

$$
G=\frac{d U}{d A}=\frac{K^{2}}{E} .
$$

The stress intensity factor is given by:

$$
K=\sqrt{E \frac{d U}{d A}},
$$

where $K$ is in $\mathrm{MPa}(\mathrm{mm})^{1 / 2}, E$ is the modulus in MPa, $U$ is the strain energy in $\mathrm{N} / \mathrm{mm}^{2}$, and $G$ or $\frac{d U}{d A}$ is the energy release rate during a small crack extension, $d A$, where $A=a \bullet b, a$ and $b$ are the crack length and the crack width, respectively, in $\mathrm{mm}$.

Once the functional forms of $K$ have been determined, the state of the stress and displacement near the crack tip region of the structure can be determined. It must be noted, however, that these equations represent a specific provision that describe the general approach to identifying these key parameters.

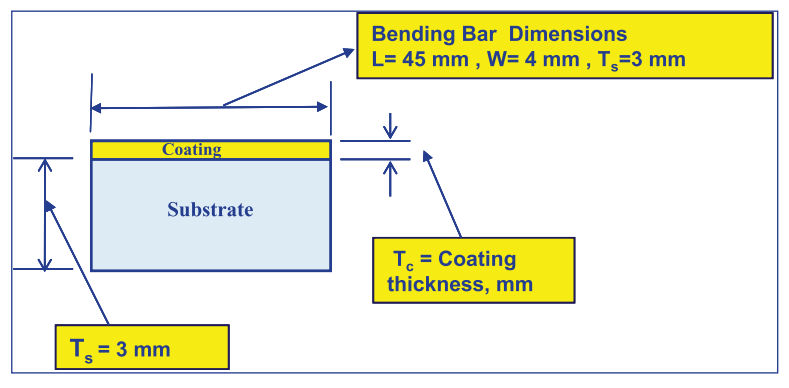

a) Schematic

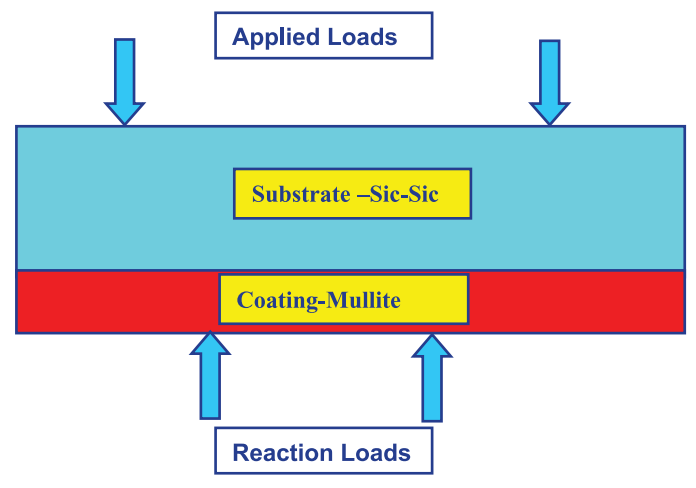

b) Four-Point Bend Test Load

Fig. 1. Schematic of the specimen dimensions and the Four-Point "Bend" Test Load set-up. 

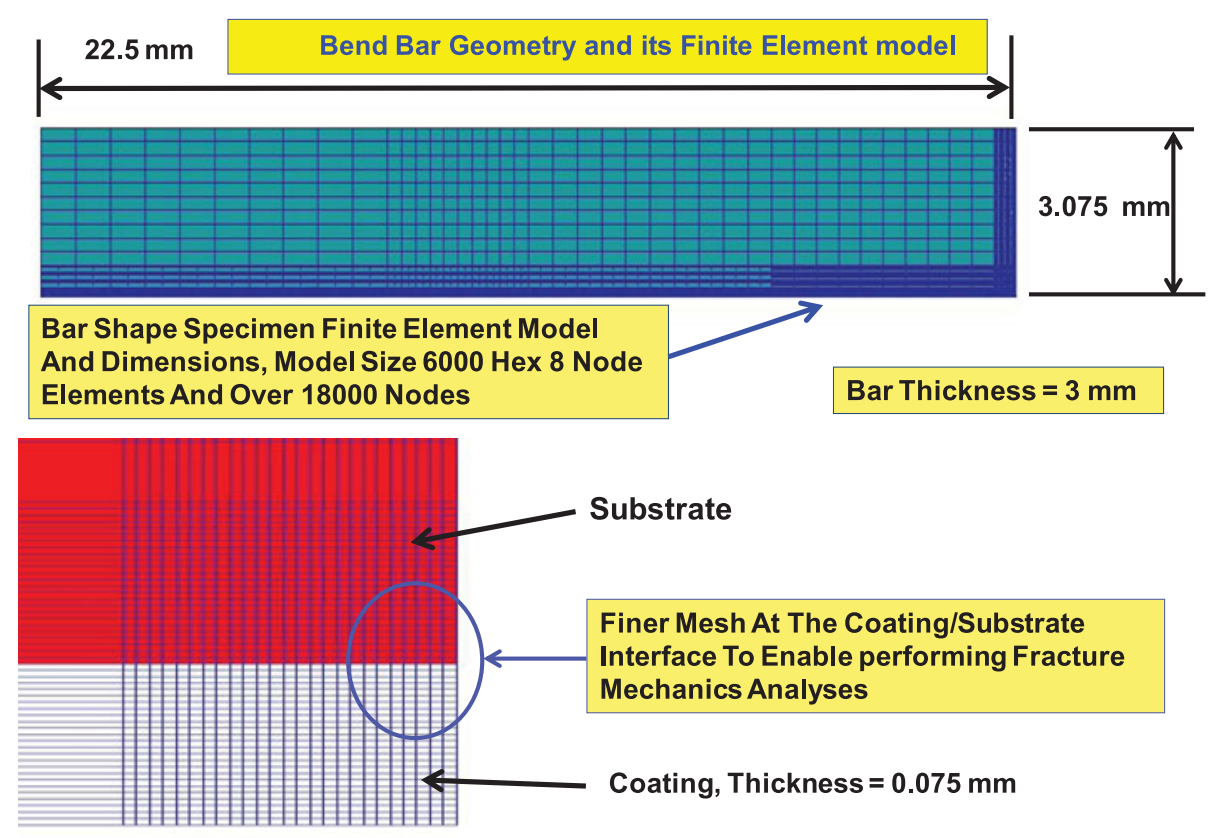

Substrate

Finer Mesh At The Coating/Substrate

Interface To Enable performing Fracture

Mechanics Analyses

Fig. 2. Specimen geometry and finite element model.

\subsection{Crack Behavior at the Interface for Four-Point Bending Condition}

The critical energy release rate due to the 4PB test of the beam specimen can be related to remote stresses that can be defined via a relationship called the J-Integral [18] shown in Eq. (3) below:

$$
G=J=\int_{s}\left(U d y-T \bullet \frac{\partial u}{\partial x} d s\right)
$$

where $u$ is the displacement vector, $y$ is the distance along the direction normal to the plane of the crack, $s$ is the arc length along the contour, $T$ is the traction vector, and $U$ is the strain energy density. For any material characterized by linear or nonlinear elastic behavior (deformation plasticity), $J$ is independent of the path $s$ taken to compute the integral [19]. Per application of the beam theory and J-integral for small scale yielding, $G$ is given by

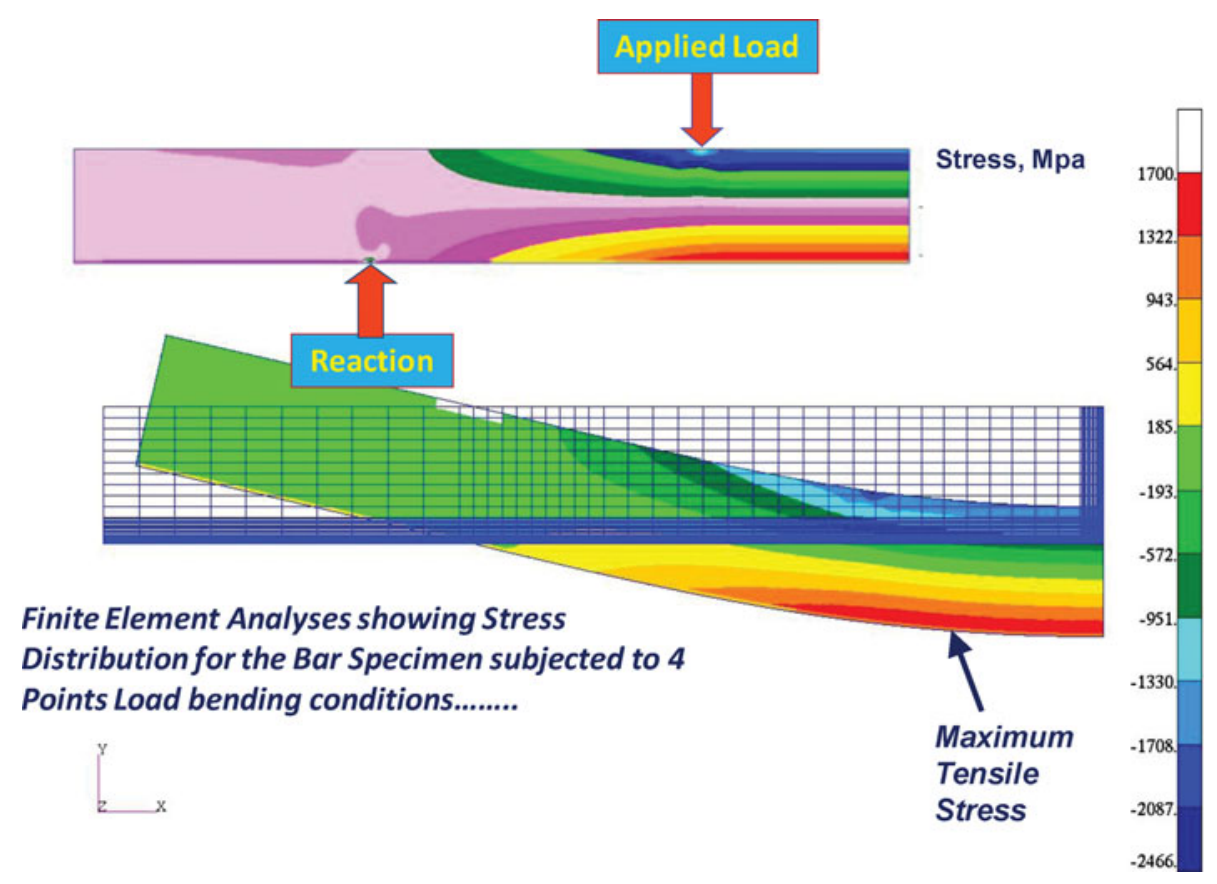

Fig. 3. In-plane stress distribution in the beam bar specimen under 4-point bending load conditions. 


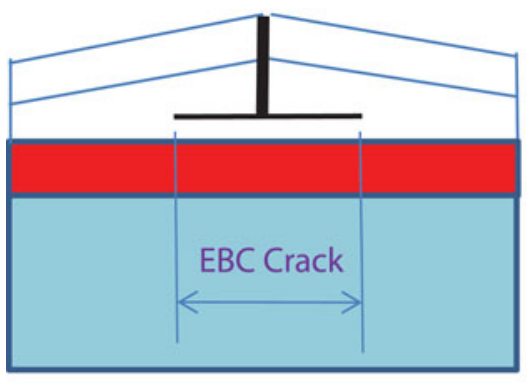

a)

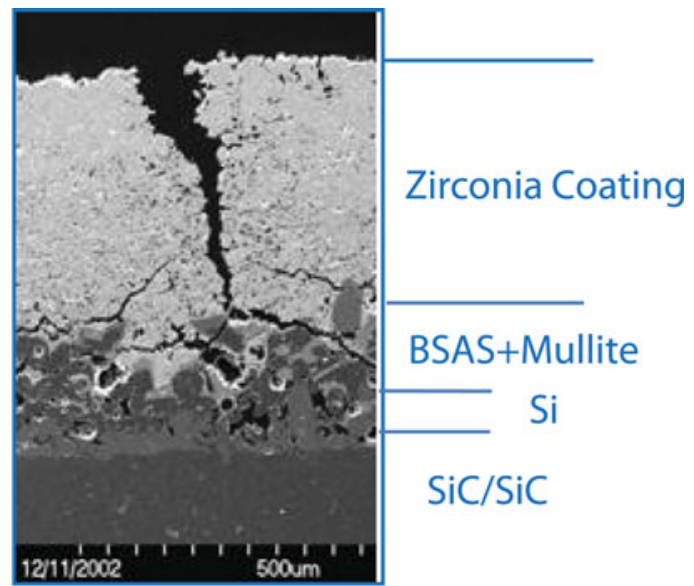

b)

Fig. 4. Assumed crack geometry: (a) EBC crack and (b) actual crack.

Eq. (4):

$$
G=J=\frac{21\left(1-v^{2}\right) M^{2}}{4 E h^{3}}
$$

where $M=\frac{P L}{2 b}$ is the bending moment; $P$ is the load applied; $L$ and $b$ are the beam length and width, respectively; $E$ is the Young modulus; $v$ is the Poisson's ratio; and $h$ is the thickness of the beam.

The stress relationship at the interface of bi-material plate with crack normal at the interface is given in the following equation (5) from reference [20]:

$$
\sigma_{i j}=\frac{K}{r^{1-\lambda}} f_{i j}(\theta)
$$

where $r$ and $\theta$ are the radial distance and the polar angle; $f_{i j}(\theta)$ represents the angular distribution of the singular stress field. The symbol $\lambda$ defines the strength of the stress singularity. It has been shown that the value of $\lambda$ is a real number between 0 and $1(0<\lambda<1)$ and is a function of the elastic properties of the present materials, which can be determined as a root of the following characteristic equation [20]:

$$
2 \lambda^{2}(\alpha-\beta)(\beta+1)-\alpha+\beta^{2}+\left(1-\beta^{2}\right) \cos (\pi \lambda)=0 .
$$

For identical elastic properties $\lambda=1 / 2$, but for material 1 stiffer than material $2, \lambda<1 / 2$, while for material 2 stiffer than material $1, \lambda>\frac{1}{2}, \alpha$ and $\beta$ are the Dundurs bi-material parameters [21], which are defined as:

$$
\alpha=\frac{E_{1}^{\prime}-E_{2}^{\prime}}{E_{1}^{\prime}+E_{2}^{\prime}} \quad \text { and } \quad \beta=\frac{\mu_{1}\left(1-2 v_{2}\right)-\mu_{2}\left(1-2 v_{1}\right)}{\mu_{1}\left(1-v_{2}\right)-\mu_{2}\left(1-v_{1}\right)},
$$

where $E_{j}^{\prime}=E_{j}$ is for plane stress, $E_{j}^{\prime}=E_{j} /\left(1-v_{j}\right)$ is for plane strain ( 1 and 2 denote the material), and $\mu$ is the shear modulus.
The parameter $\alpha$ approaches +1 when the stiffness of material 1 (TBC) is extremely large compared to the stiffness of material 2 (substrate), and both parameters become zero in the case of homogenous material systems. If the two materials 1 and 2 are switched both $\alpha$ and $\beta$ changes signs. If a crack reaches an interface, there are at least three possible crack paths for the crack tip. Figure 5 shows a schematic prediction for the simplest possible crack paths in a bi-material model: (a) crack penetration across the interface; (b) crack deflection on one side of the interface (singly deflected crack); and (c) crack defection on both sides (doubly deflected crack).

For a crack perpendicular to the interface and under applied load parallel to the interface, the strain energy release rates as a function of crack extension $G_{d}$ along the interface (deflection) and $G_{p}$ into the interface (penetration) are well known to be of the forms [20-24]:

$$
\begin{aligned}
G_{d} & =\frac{\left[\frac{1-v_{1}}{\mu_{1}}+\frac{1-v_{1}}{\mu_{2}}\right]}{4 \cosh ^{2} \pi \varepsilon}\left(K_{1}^{2}+K_{2}^{2}\right), \\
G_{p} & =\frac{1-\nu_{2}}{2 \mu_{2}} K_{p}^{2} .
\end{aligned}
$$

In Eqs. (7) and (8), $G_{d}$ (material 1) is the energy release rate associated with the "deflected" crack or adhesive failure and $G_{p}$ (material 2) is the energy release rate associated with the "penetrated" crack (or cohesive failure of adjacent

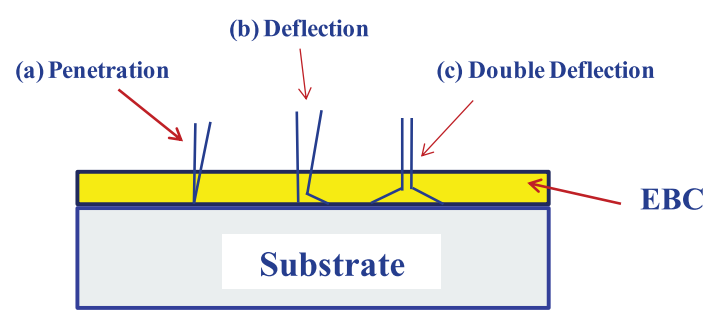

Fig. 5. Typical crack penetration-deviation situations. 


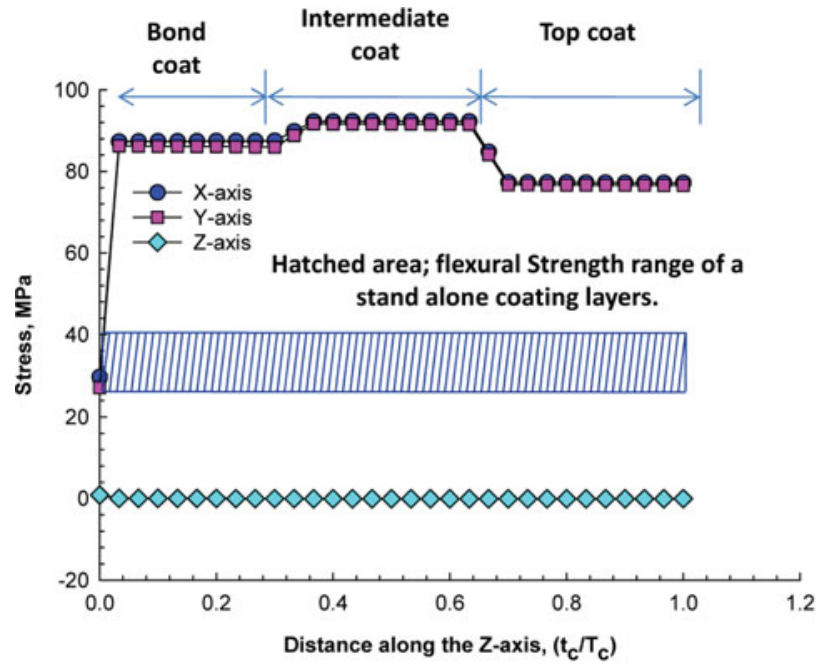

(a) Coating

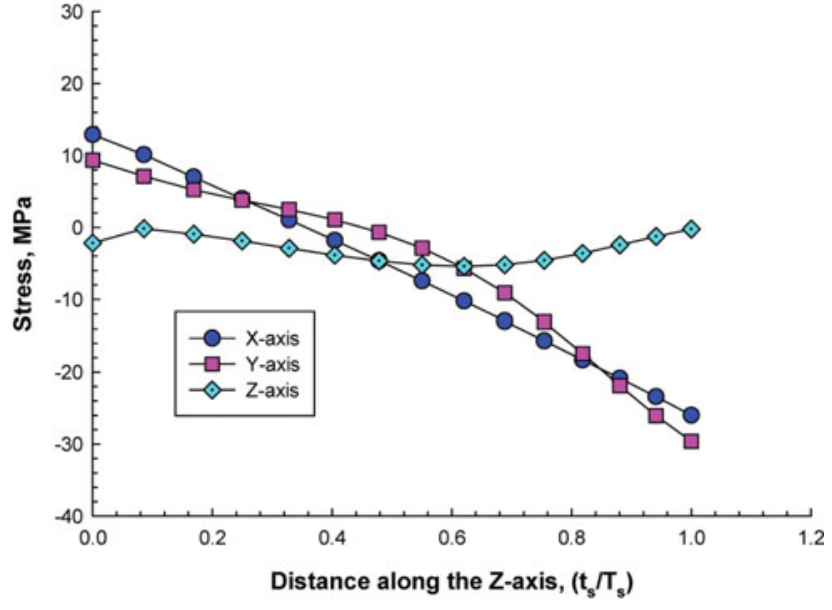

(b) Substrate

Fig. 6. Predicted variation of thermal residual in-plane stress vs. normalized distance for coating system. The hatched area indicates typical flexural strength range of stand-alone coating layers.

material). Similarly, $G_{p c}$ is the cohesive or penetrated fracture energy and $G_{d c}$ is the adhesive or deflected fracture energy, respectively; $K_{1}$ and $K_{2}$ are the stress intensity factors for the interface crack; $K_{p}$ is the stress intensity factor for the case of penetration. $\varepsilon$ is a function of material constants:

$$
\varepsilon=\frac{1}{2 \pi} \ln \left(\frac{1-\beta}{1+\beta}\right)
$$

The condition for crack deflection can be expressed as flows [19-23]:

$$
\frac{G_{d}}{G_{p}}>\frac{G_{d c}}{G_{p c}} .
$$

The preferred outcome in a 4PB test is that the crack will deflect along the interface. The relative value of these parameters governs the criterion for the crack deflecting along the interface versus penetrating through it. According to first principles of the linear elastic fracture mechanics (LEFM) theory, the crack will tend to grow along the interface (deflect) if the condition of Eq. (10) is true. Otherwise, the crack will tend to grow through the interface and penetrate into the adjacent material (cohesive failure). However, if Eq. (10) is equality, then the crack can go either way.

\section{Results and Discussion}

The analyses covered data obtained from a prior analysis [25] that investigated in great detail the impact of the thermal residual stresses due to the coating application. These data were all incorporated and utilized in the current study; thus, their influence is fully accounted for. For instance, Figure 6 shows the stresses in the bar specimen due to the thermal loading applied for both the coating and the substrate. These results are for the coating system and the substrate, respectively. The coating and substrate thickness is designated by the symbols $t_{c}$ and $t_{s}$ and they represent the incremental thickness of the coating and the substrate respectively, while $T_{c}$ and $T_{s}$ are the total thickness of each entity. The location at the substrate/coating interface is represented by a ratio of zero for $\frac{t_{c}}{T_{c}}$, while a ratio of unity represents maximum coating thickness.

A similar convention is used concerning the ratio of the substrate thickness arrangement, i.e., $\frac{t_{s}}{T_{s}}$ corresponds to maximum substrate thickness, In Figure $6 \mathrm{a}$, the stresses along the thickness, $Z$-axis, and along the $X-Y$ axes are shown as a function of the normalized distance. The normalized distance is defined as the ratio of the length increment divided by the total thickness. It is reported from the data presented that the $X-Y$ stresses are much higher than the through thickness stress; in fact, the through thickness stresses are nearly negligible as anticipated. But maximum in-plane stresses can be significant depending on the composition of the constituent layer and the distance from the substrate. Figure $6 \mathrm{~b}$ shows these stresses along the $X, Y$, and $Z$ axis through the substrate. Their magnitude is relatively small. The hatched area in the figure indicates typical flexural strength range of stand-alone coating layers. Reducing the elastic modulus and the coefficient of thermal expansion will result in lowering stress response. Additional information can be obtained from [25].

Figures 7 to 9 represent the results obtained from the analyses conducted and their relevant impact on the findings. The finite element model of the bend bar specimen under 4 PB loading conditions and the results obtained from the finite element fracture mechanics analyses employ crack advancement in two directions; parallel and perpendicular to the coatingsubstrate interface are shown in Figure 7. 


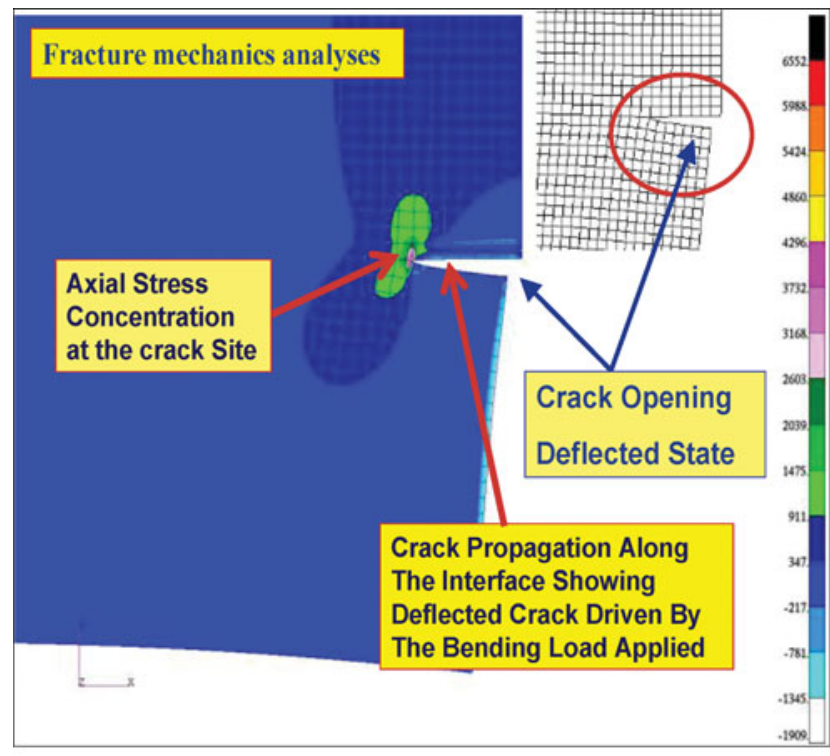

a) Deflecting Case

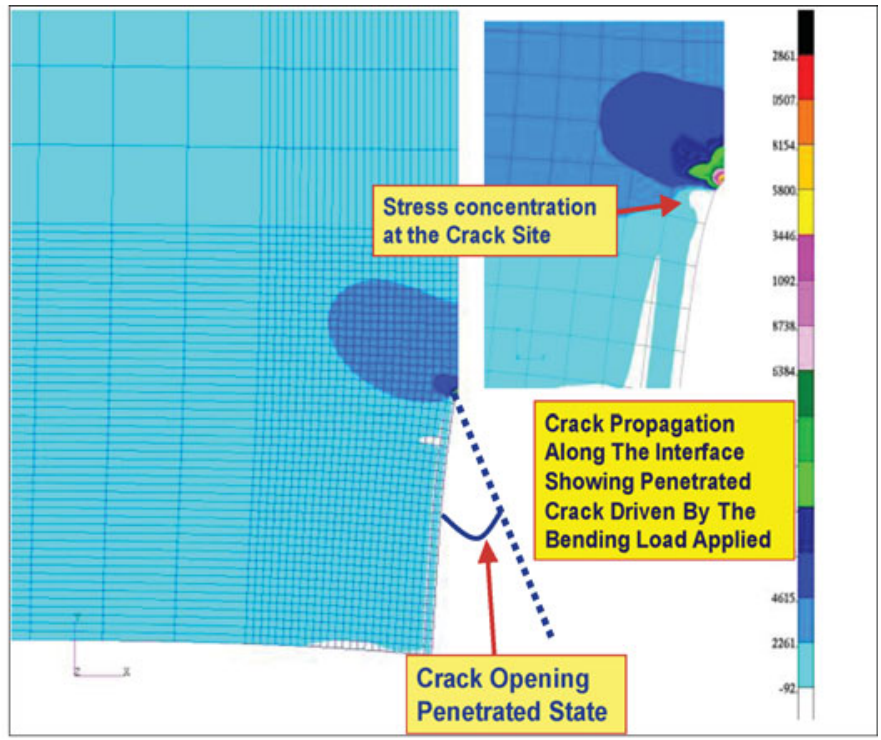

b) Penetrating Case

Fig. 7. Fracture mechanic analyses showing an advanced crack parallel to the coating-substrate interface.

Moreover, shown in Figures $7 \mathrm{a}$ and $7 \mathrm{~b}$ are the deflected and the penetrating cracks' propagation contour plots. The analyses assumed combined residual stress effects and mechanical loading due to the procedure of coating application (thermal effects) and bending. Very fine mesh was employed at the crack/interface region to ensure accuracy, and a confined stress concentration as expected is seen at the crack site for both deflection and penetration situations. Crack opening in both cases analyzed, deflected, and penetrated are clearly seen along with the stress directions, axial stress along the $x$-axis in the case of deflection and along the $y$-axis in the case of penetration.

It is also noted in both Figures $7 \mathrm{a}$ and $7 \mathrm{~b}$ that the crack is advanced to calculate the strain energy rate at small crack increments in order to establish the conditions where the crack behavior can be validated through Eq. (10). Three different coating thicknesses were considered for the analyses, a thickness size of 25,75 , and $125 \mu \mathrm{m}$, respectively. The strain energy release rate is determined for each coating size. The strain energy release rate for all three coating thicknesses analyzed for both the deflected and the penetrated cracks are shown in Figures $8 \mathrm{a}$ and $8 \mathrm{~b}$. It is noted that the strain energy increases as the normalized crack length (ratio of the crack size/the coating thickness) $(a / t)$ increases for the penetrated crack case for the 0.025- and 0.075-mm thicknesses, while for the 0.125$\mathrm{mm}$ thickness case minimal changes are noted. While for the deflecting crack case, the strain energy release decreases as the $(a / t)$ increases indicating that a completely different behavior from that of the deflected is apparent.

As one would expect intuitively, the competition between deflection and penetration becomes more favorable to deflection the more oblique the crack impinging the interface is.
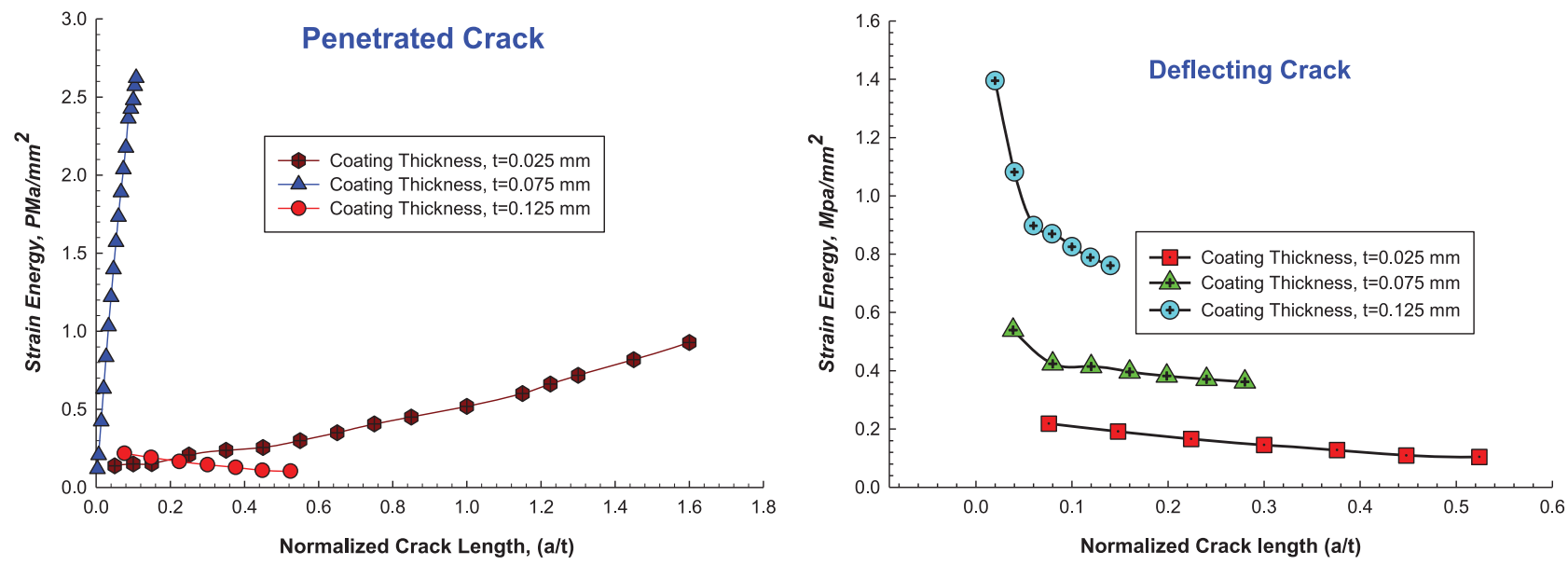

Fig. 8. Strain energy release rate as a function of normalized crack length. 


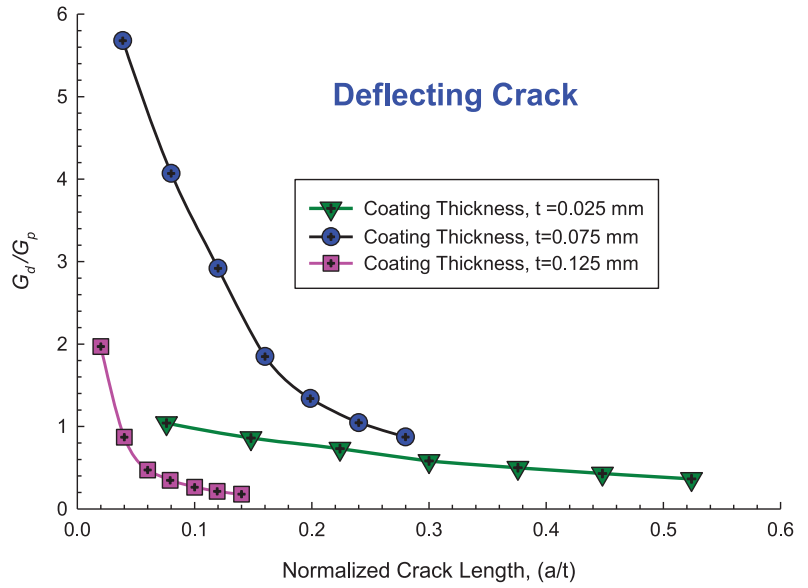

a) Penetrated Crack

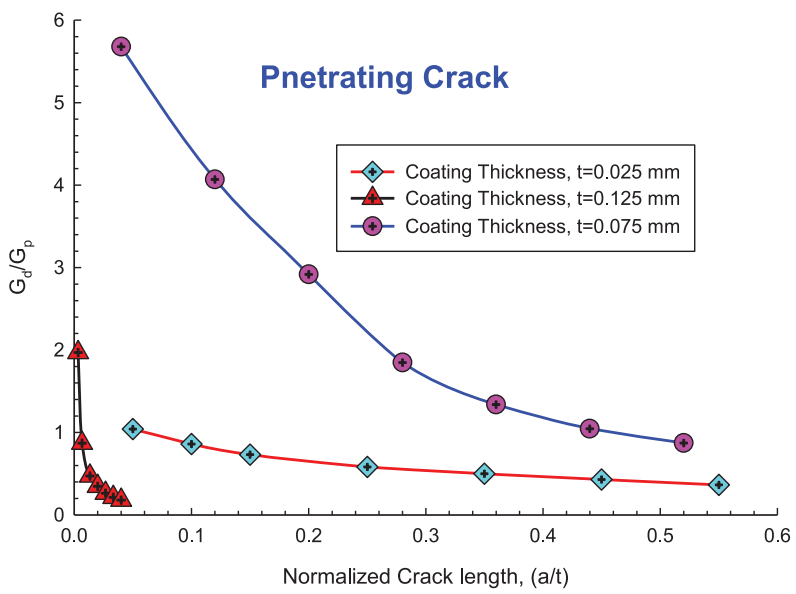

(b) Deflected Crack

Fig. 9. Strain energy release ratio as a function of normalized crack length.

It is also noted that in the penetrated case even though the geometry of the beam and the coating-interface region were meshed for each thickness to accommodate the crack size, avoid discontinuities, and preserve proper loading conditions, the performance of the data did not turn as anticipated. Several factors can be attributed to such conduct and among them is the lack of higher sensitivity finite element mesh of the beam specimen, although the advanced paver option within the MSC/Patran [12] was used to acquire quad elements of equal edge length along and perpendicular to the interface to enable the simulation of adhesive and cohesive failure. In spite of this watchful meshing approach, the shapes of the elements remained to cause fluctuations in the strain energy results. Thus, the mesh refinement at the interface is very critical to the crack advancement, propagation, and is equally sensitive to any other small modeling variations to an extent that the result's outcome as noted in the case of the $0.075-\mathrm{mm}$ coating thickness is affected.

Figures $9 \mathrm{a}$ and $9 \mathrm{~b}$ represent the variation of the ratio of the energy release rate of the deflecting and the penetrating cracks along the interface, respectively, as a function of the normalized crack length. It is very clear from the graph that for both situations, deflected and penetrated, for a lower $a / h$, $G_{d} / G_{p}$ increases indicating a higher chance of a deflectedpenetrating crack and a successful test.

The data further shows that at any given crack size it can easily be determined in which direction the crack will shift provided that the conditions of Eq. (10) are applicable. Finite values of deflected and penetrated cracks can thus play an important role in determining the tendency for interfacial crack detection, which in turn then controls the toughness of the entire substrate.

The present results provide a guideline for estimating detection versus penetration for various elastic parameters, interface toughness, and crack extension. Moreover, it is also obvious from the charts shown in Figure 9 that regardless of the coating thickness size, the trend or the variation routine of the ratio of the energy release rate was similar under both crack deflection and penetration conditions. It should be noted further that not including experimental data due to not being readily available may have hindered the affirmation of the findings to some extent. It is planned to add such data and provide comparative data in future publications.

\section{Conclusions}

An analytical evaluation using a fracture mechanics-based finite element approach to examine impingement of crack behavior at the interface of EBC-ceramic substrate to establish a relationship that leads to determine when the crack is arrested or advanced by either penetrating the interface or deflecting onto the interface is performed. A finite element mesh model of a bend bar specimen under 4-point loading conditions is generated. The analyses assume the combined residual stress effects and mechanical loading due to both procedures of coating application and bending load. The energy release rate for the deflected crack is compared with that of the energy release rate for the penetrating crack. The results obtained for both situations, deflected and penetrated, shows that for a lower normalized crack length $(a / t)$, strain energy release rate for the deflected/penetrated crack $\left(G_{d} / G_{p}\right)$ increases indicating a higher chance of both deflected or penetrating crack and a successful test. The data reported show that at any given crack size it can easily be determined at which direction the crack will shift provided that the conditions of Eq. (10) are met. The results presented are preliminary and are only for one layer of coating, though, future work is planned to include multilayer coating conditions accompanied with higher geometric modeling mesh sensitivities, experimental testing, and specialized analytical studies.

\section{References}

[1] H. Liu and S. H. Hsu, Fracture behavior of multilayer silicon nitride/boron nitride ceramics, J. Am. Ceram. Soc., vol. 77, no. 8, pp. 2081-2087, 1994. 
[2] G.E. Hilmas, G.S. Brady, and J.W. Halloran, $\mathrm{SiC}$ and $\mathrm{Si}_{3} \mathrm{~N}_{4}$ fibrous monoliths: Non-brittle fracture from powered processed ceramics produced by co extrusion. In: Ceramic Transactions, Vol. 51, Ceramic Processing Science and Technology, H. Hauser, G.L. Messing, and S.I. Hirano, Eds., American Ceramic Society, Westerville, $\mathrm{OH}$, pp. 609-614, 1994.

[3] D. Kovar, B.H. King, R.W. Trice, and J.W. Halloran, Fibrous monolithic ceramics, J. Am. Ceram. Soc., vol. 80, no. 10, pp. 2471-2487, 1997.

[4] J. Cook and J.E. Gordon, A mechanism for the control of crack propagation in all-brittle systems, Proc. R. Soc. London, vol. 282, pp. 508-520, 1964.

[5] W. Lee and W.J. Clegg, The deflection of cracks at interfaces, Key Eng. Mater., vol. 116-117, pp. 193-208, 1996.

[6] D. Kovar, M.D. Thouless, and J.W. Halloran, Crack deflection and propagation in layered silicon nitride/boron nitride ceramics, J. Am. Ceram. Soc., vol. 81, no. 4, pp. 1004-1012, 1998.

[7] A. Abdul-Aziz and R.T. Bhatt, Influence of cooling hole geometry and material conductivity on the thermal response of cooled silicon nitride plate. In: Proceedings of the 26th Annual Conference on Composites, Advanced Ceramics, Materials, and Structures, H-T Lin and M. Singh, Eds., The American Ceramic Society, Cocoa Beach, Florida, pp. 125-132, 2002.

[8] A. Abdul-Aziz, A, L.J. Ghosn, G. Baaklini, and R. Bhatt, A combined NDT/finite element technique to study the effects of matrix porosity on the behavior of ceramic matrix composites, J. Mater. Eval., vol. 61, no. 11, pp. 1217-1221, 2003.

[9] O. Jaimenez, J. McClain, B. Edwards, V. Parthasarathy, H. Bhageri, and G. Bolander, Ceramic stationary gas Turbine development program-Design and test of a ceramic turbine blade. In: ASME 1998 International Gas Turbine and Aeroengine Congress and Exhibition, Volume 5: Manufacturing Materials and Metallurgy; Ceramics; Structures and Dynamics; Controls, Diagnostics and Instrumentation; Education, Stockholm, Sweden, June 2-5, 1998.

[10] T. Itoh, Y. Yoshida, S. Sasaki, M. Sasaki, and H. Ogita, Japanese Automotive Ceramic Gas Turbine Development, Vol. 1, M. van Roode, M.K. Ferber, and D.W. Richerson, Eds., The American Society of Mechanical Engineers, New York, pp. 283-303, 2002.

[11] D.M. Zhu, R.A. Miller, and D.S. Fox, Thermal and environmental barrier coating development for advanced propulsion engine systems, NASA Report TM-2008-215040, 2008.
[12] MSC/PATRAN Graphics and Finite Element Package, The MacNeal-Schwendler Corporation, Costa Mesa, CA, 2007.

[13] MSC/Marc General Purpose Finite Element Analysis Program, The MacNeal-Schwendler Corporation, Costa Mesa, CA, 2007.

[14] K.N. Lee, R.A. Miller, and N.S. Jacobson, New generation of plasma-sprayed mullite coatings on silicon-carbide, J. Am. Ceram. Soc., vol. 78, no. 3, pp. 705-710, 1995.

[15] J.C. Nagtegaal and J.E. de Jong, Some computational aspects of elastic-plastic large strain analysis, Int. J. Numer. Methods Eng., vol. 17 , pp. $15-41,1981$.

[16] J.R. Rice and D.M. Tracy, Computational fracture mechanics. In: Proceedings of the Symposium on Numerical and Computer Methods in Structural Mechanics, S.J. Fenves, N. Perrone, A.R. Robinson, and W.C. Schnobrich, Eds., Academic Press, New York, pp. 585-623, 1973.

[17] P.C. Paris and F. Erdogan, A critical analysis of crack propagation laws, J. Basic Eng., vol. 85, pp. 528-534, 1963.

[18] J.R. Rice, A path independent integral and the approximate analysis of strain concentration by notches and cracks, J. App. Mech., vol. 35 , p. $379,1986$.

[19] S. Roham, K. Hardikar, and P. Woytowitz, Crack penetration and deflection at a biomaterial interface in a four-point bend test, $\mathrm{J}$. Mater. Res., vol. 19, no. 10, pp. 3019-3027, 2004.

[20] K. Kaddouriet al., Finite element analysis of crack perpendicular to bi-material interface: Case of couple ceramic-metal, Comput. Mater. Sci., vol. 35, pp. 53-60, 2006.

[21] M.Y. He, and J.W. Hutchinson, Crack deflection at an interface between dissimilar elastic materials, Int. J. Solids Struct., vol. 25, no. 9, pp. 1053-1067, 1989.

[22] D.H. Chen, A crack normal to and terminating at a bi-material interface, Eng. Fract. Mech., vol. 19, pp. 517-532, 1994.

[23] J. Dundurs, Effect of elastic constants on stress in a composite under plane deformation, J. Compos. Mater., vol. 1, pp. 310-322, 1969.

[24] M.Y. He, A.G. Evans, and J.W. Hutchinson, Crack deflection at an interface between dissimilar elastic materials: Role of residual stresses, Int. J. Solids Struct., vol. 31, pp. 3443-3455, 1994.

[25] A. Abdul-Aziz and R.T. Bhatt, Thermal residual stress in environmental barrier coated silicon nitride-modeled, The American Ceramic Society 33rd International Conference and Exposition on Advanced Ceramics and Composites, January 18-23, Daytona Beach, Florida, 2009. 